\section{BMJ Open Respiratory Research}

\title{
Ciprofloxacin DPI: a randomised, placebo-controlled, phase IIb efficacy and safety study on cystic fibrosis
}

\author{
Henry L Dorkin, ${ }^{1}$ Doris Staab, ${ }^{2}$ Elisabeth Operschall, ${ }^{3}$ Jeff Alder, ${ }^{4}$ Margarita Criollo ${ }^{5}$
}

To cite: Dorkin HL, Staab D, Operschall E, et al. Ciprofloxacin DPI: a randomised, placebocontrolled, phase Ilb efficacy and safety study on cystic fibrosis. BMJ Open Resp Res 2015:2:e000100. doi:10.1136/bmjresp-2015000100

Received 27 June 2015 Revised 25 September 2015 Accepted 30 September 2015

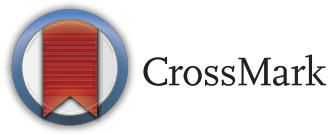

${ }^{1}$ Department of Respiratory Diseases, Children's Hospital Boston, Boston, Massachusetts, USA ${ }^{2}$ Charité Campus VirchowKlinikum, Berlin, Germany ${ }^{3}$ Bayer Pharma AG, Berlin, Germany

${ }^{4}$ Bayer HealthCare, Whippany, New Jersey, USA

${ }^{5}$ Bayer Inc, Mississauga, Ontario, Canada

Correspondence to Dr Margarita Criollo; margarita.criollo@bayer.com

\section{ABSTRACT}

Background: Treatment of infective bronchitis involving Pseudomonas aeruginosa is a cornerstone of care in patients with cystic fibrosis (CF). This phase $\mathrm{Ilb}$, randomised, double-blind, placebo-controlled study assessed the efficacy and safety of ciprofloxacin dry powder for inhalation (DPI) in this population.

Methods: Patients with $\mathrm{CF}, \geq 12$ years of age $(\mathrm{N}=286)$, were randomised to ciprofloxacin DPI $(32.5 \mathrm{mg}(\mathrm{n}=93)$ or $48.75 \mathrm{mg}(\mathrm{n}=93))$, or corresponding placebo (32.5 mg, $n=65 ; 48.75 \mathrm{mg}, \mathrm{n}=35$ ) twice daily for 28 days. The primary objective was the change in forced expiratory volume in $1 \mathrm{~s}$ (FEV1) from baseline (day 0 ) to end of treatment (day 29) in the intent-totreat population for ciprofloxacin DPI compared with the corresponding placebo group.

Results: The primary effectiveness objective was not met; there were no significant differences in change in FEV1 between ciprofloxacin DPI and the corresponding placebo group for either dose $(p=0.154)$. However, in pooled analyses, FEV1 decline from baseline to treatment end was significantly lower with ciprofloxacin DPI than with placebo (pooled data; $p=0.02$ ). Ciprofloxacin DPI showed positive effects on sputum bacterial load and quality of life, but these effects were not maintained at the 4-week follow-up. Ciprofloxacin DPI was well tolerated and there were no significant differences in type/incidence of treatment-emergent adverse events by treatment group ( $p=0.115)$.

Conclusions: Further investigations are needed to determine the full scope of the beneficial effects of ciprofloxacin DPI for patients with CF.

Trial registration number: Clinicaltrials.gov NCT00645788; EudraCT 2008-008314-40.

\section{INTRODUCTION}

Cystic fibrosis (CF) is a chronic, incurable and life-shortening disease, with respiratory failure resulting from chronic pulmonary infection accounting for the majority of deaths. ${ }^{12}$ Treatment of chronic respiratory infection is therefore a cornerstone of $\mathrm{CF}$ care. ${ }^{1}$ Of the organisms responsible for pulmonary infection in CF, Pseudomonas aeruginosa is one of the most prevalent, ${ }^{1}$ with an

\section{KEY MESSAGES}

In this placebo-controlled, randomised, phase Ilb clinical trial, 288 adolescent and adult patients with cystic fibrosis were assigned to receive placebo or ciprofloxacin dry powder for inhalation (DPI) (doses of $32.5 \mathrm{mg}$ or $48.75 \mathrm{mg}$ ) twice daily for 29 days.

There were no significant differences in the primary efficacy end point of change in forced expiratory volume in $1 \mathrm{~s}$ (FEV1) between ciprofloxacin DPI and the corresponding placebo group for either dose, but in pooled analyses, ciprofloxacin DPI was associated with a significantly lower decrease in FEV1 compared with placebo.

Although this study did not achieve its primary efficacy end point, ciprofloxacin DPI showed signs of efficacy, and was safe and well tolerated during treatment.

estimated $50.6 \%$ of patients chronically infected with this pathogenic bacteria in the USA in 2011. ${ }^{3}$ Management of chronic infection consists of airway clearance using techniques such as postural drainage, chest compression, oscillatory positive expiratory pressure or exercise, ${ }^{4}$ combined with antibiotic treatment. Antibiotics may be administered orally, via an intravenous line or via inhalation. $^{5}$

The most frequently used US Food and Drug Administration (FDA)-approved inhaled antibiotics require the use of compressors and nebulisers, and may require long treatment durations. ${ }^{6}$ Furthermore, nebulisers need to be carefully cleaned after use, and these treatments are relatively expensive to employ. All these factors are barriers to the effective use of this mode of administration. $^{6}{ }^{7}$ Dry powder inhalers, which are small, portable, breath-actuated devices, ${ }^{8}$ have proven useful in the treatment of asthma and other respiratory conditions. ${ }^{6}$ Importantly, they can be administered within a short period of time, thereby helping to 
reduce the burden of treatment. This is an essential factor to consider in a patient population that spends an average of $2 \mathrm{~h}$ daily on healthcare-related activities. ${ }^{9} 10$ An important aspect of the CF therapeutic drug development pipeline has been to develop a wider range of agents and delivery systems to treat $P$. aeruginosa respiratory infection, ${ }^{11}$ such as the recently approved aminoglycoside antibiotic tobramycin DPI (TOBI Podhaler). ${ }^{12}$ Despite this approval, there is still a clinical need for antibiotics that can be administered via the DPI route for the treatment of $P$. aeruginosa in patients with CF. ${ }^{6} 1113$

Ciprofloxacin DPI is a fluoroquinolone antibiotic manufactured using PulmoSphere technology from Novartis (Novartis Pharma AG, Basel, Switzerland) and consists of particles of a controlled size of $\leq 5 \mu \mathrm{m}$, with powder density and morphology optimised for pulmonary delivery. ${ }^{14}{ }^{15}$ The drug is administered using a capsule-based dry powder inhaler device (T-326 inhaler). ${ }^{16}$ This formulation of the antibiotic has properties that lead to markedly reduced systemic absorption, thus enhancing its action and potentially minimising side effects. ${ }^{13}{ }^{16-18}$ After decades of intensive antibiotic use, there is now accelerated evolution of antibiotic resistance. New treatment options administered by inhalation could help counter the increasing drug resistance and improve efficacy. ${ }^{11}{ }^{19}$ Approval of this agent would provide CF physicians and patients with a new option for antipseudomonal treatments administered through the DPI route.

The mechanism of action of ciprofloxacin is distinct from other agents commonly administered by inhalation, such as tobramycin. ${ }^{20}$ Ciprofloxacin has frequently been used via oral or intravenous administration for the treatment of pulmonary infection in $\mathrm{CF}^{21}{ }^{22}$ Therefore, a clinical trial of the new DPI formulation was considered appropriate to perform. A double-blind, prospective, randomised phase IIb trial was designed to assess the efficacy and safety of ciprofloxacin DPI in patients with $\mathrm{CF}$, over a 4 -week period.

\section{METHODS}

\section{Study design}

This multicentre, phase IIb, randomised, double-blind, parallel-group, placebo-controlled study (Clinicaltrials. gov trial registration number: NCT00645788; EudraCT number: 2008-008314-40) was conducted at 73 centres: USA (51), Canada (3), Germany (4), Sweden (3), Denmark (1), Israel (4), UK (1) and Australia (6). All study personnel and participants were blinded with respect to active treatment (ciprofloxacin DPI, formulated by Novartis' PulmoSphere technology, or placebo), but not to dose. The study protocol was amended several times after enrolment started; the most important changes were the inclusion of children aged 1217 years on availability of safety and pharmacokinetic data, and the addition of a higher ciprofloxacin DPI dose group ( $48.75 \mathrm{mg})$ approximately 1 year after the first participants were enrolled. The decision to add the higher dose was based on the good safety results with the $32.5 \mathrm{mg}$ dose and the desire to investigate more than one dose in the phase II trial. Investigation of the higher dose was also recommended by regulatory authorities to help to determine the most appropriate doses to carry forward into the phase III programme.

Participants were stratified according to maintenance macrolide usage (ie, participants currently treated with macrolide vs participants not currently treated with macrolide), and randomised 2:2:2:1 to $32.5 \mathrm{mg}$ ciprofloxacin DPI (corresponding to $50 \mathrm{mg}$ dry powder); placebo corresponding to $32.5 \mathrm{mg}$ ciprofloxacin DPI; $48.75 \mathrm{mg}$ ciprofloxacin DPI (corresponding to $75 \mathrm{mg}$ dry powder); or placebo corresponding to $48.75 \mathrm{mg}$ ciprofloxacin DPI (figure 1A). All treatments were given twice daily for 29 days ( \pm 1 day). Global Biostatistics, Bayer Pharma AG, assigned the randomisation and drug pack numbers using a central, secure randomisation system. These assignments were then communicated via an interactive voice-response system. All patients maintained their standard treatment, which may have included Pulmozyme (dornase $\alpha$ ), albuterol, inhaled steroids, macrolides, saline inhalation and $\beta$-agonists (long-acting and short-acting) (stable regimen $\geq 30$ days prior to study drug administration).

\section{Eligibility}

Participants with a documented diagnosis of $\mathrm{CF}$ and chronic colonisation with $P$. aeruginosa, who were in a stable clinical condition and on a stable treatment regimen, were eligible for inclusion in the trial. The main inclusion criteria were age $\geq 12$ years and CF diagnosed by clinical findings and one of the following: a positive sweat chloride test; homozygosity for $\Delta \mathrm{F} 508$ genetic mutation or a compound heterogeneous genotype for two known CF mutations; a positive sputum or throat swab culture for $P$. aeruginosa within the previous 12 months. Participants were also required to meet specific entry criteria at the screening visit, specifically: a stable pulmonary status with forced expiratory volume in $1 \mathrm{~s}$ (FEV1) $\geq 35 \%$ to $\leq 75 \%$; room air oximetry $\geq 88 \%$ saturation; absence of antibiotic treatment (with the exception of macrolides, which were allowed concomitantly as part of the standard treatment regimen) for pulmonary exacerbation within 30 days before study drug administration (non-antipseudomonal antibiotics were allowed for other indications); or a stable treatment regimen for 30 days before and throughout the study duration. Patients on long-term on-off cycles of tobramycin or colistin treatment for CF were enrolled in their month off, and visits were scheduled to ensure that the start of study treatment was not delayed beyond the minimum 30-day washout period.

The main exclusion criteria included: findings on screening history and physical examination unrelated to $\mathrm{CF}$ that could affect efficacy measurements; colonisation 

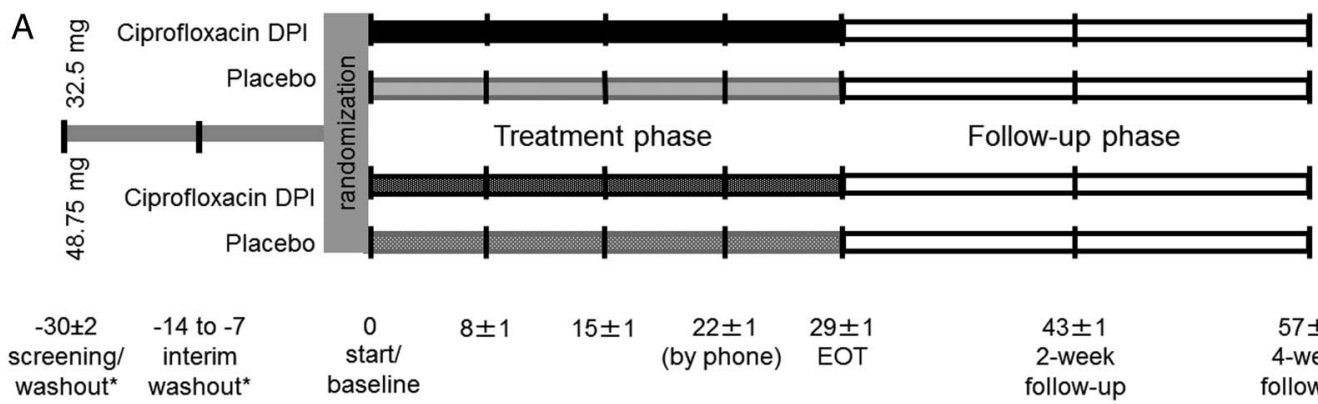

$43 \pm 1$
2 -week
follow-up

$57 \pm 1$

washout $^{\star}$ washout ${ }^{\star}$ baseline

*Subjects who were on inhaled aminoglycoside maintenance therapy were enrolled in their off-therapy period. If screening was not possible immediately post-aminoglycoside cycle completion \pm 2 days, the first screening visit was skipped to avoid extending the off-therapy period for more than 30 days

B

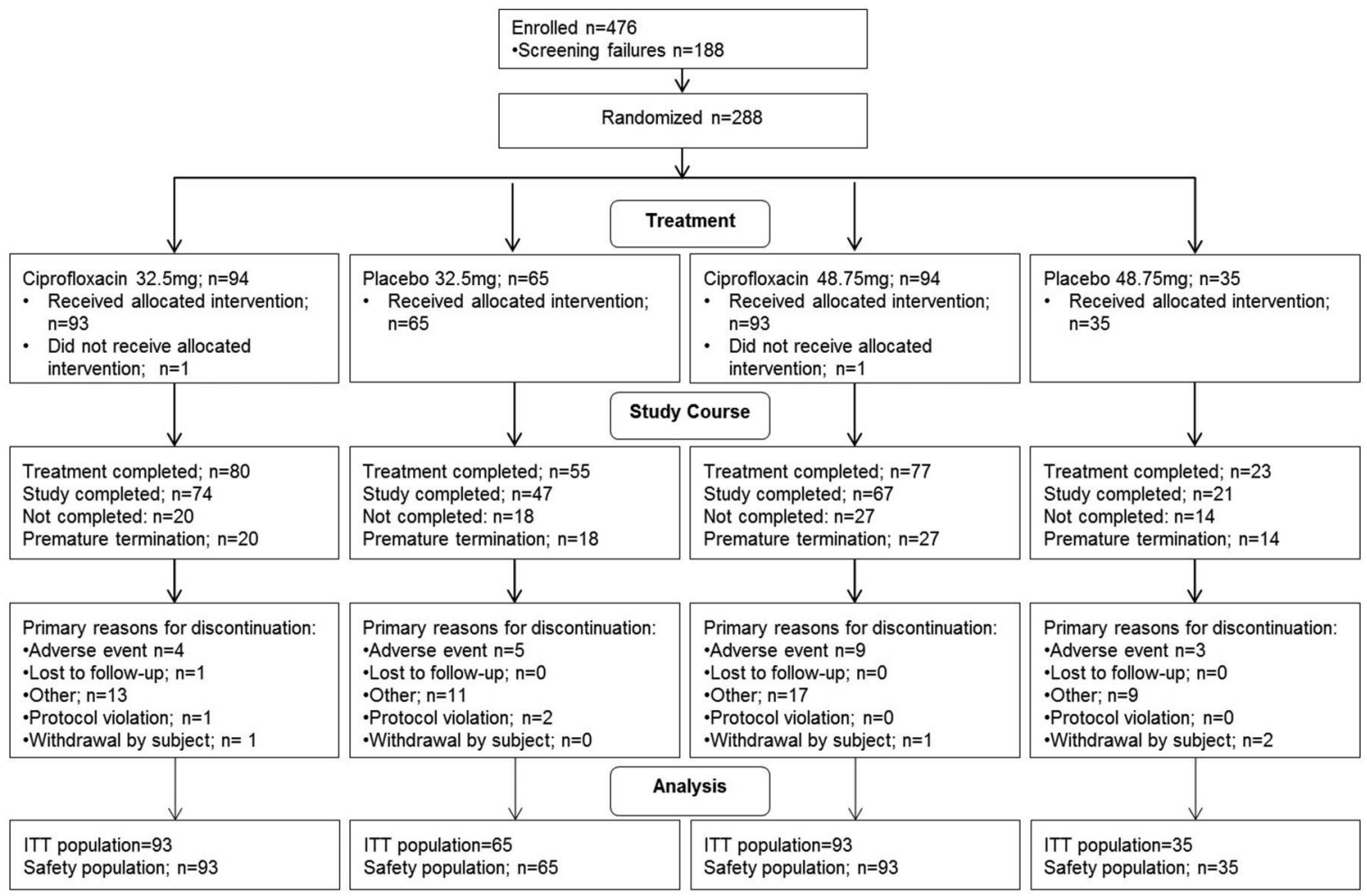

ITT, intent to treat

Figure 1 Study design (A) and subject disposition (B). (A) Subjects were stratified based on maintenance macrolide usage and randomised 2:2:2:1 to receive twice daily: $32.5 \mathrm{mg}$ ciprofloxacin DPI (corresponding to $50 \mathrm{mg}$ dry powder); placebo corresponding to $32.5 \mathrm{mg}$ ciprofloxacin DPI; $48.75 \mathrm{mg}$ ciprofloxacin DPI (corresponding to $75 \mathrm{mg}$ dry powder); or placebo corresponding to $48.75 \mathrm{mg}$ ciprofloxacin DPI for 29 days ( \pm 1 day). DPI, dry powder for inhalation; EOT, end of treatment. (B) A total of 288 patients were randomised. Of these, 286 received either study drug or placebo, and were included in both the ITT and safety analyses sets. ITT, intent-to-treat.

with $P$. aeruginosa and a ciprofloxacin minimum inhibitory concentration (MIC) of $\geq 256 \mu \mathrm{g} / \mathrm{mL}$; respiratory tract colonisation with Burkholderia cepacia complex within the preceding 12 months; symptomatic aspergillosis; haemoptysis $\geq 300 \mathrm{~mL}$ or requiring blood transfusion within the preceding 4 weeks; a history of severe allergies; pregnancy; and participants <18 years with chronic musculoskeletal disease or abnormal musculoskeletal evaluation at baseline, a high risk of chronic or recurrent arthritis or tendonitis, or a history of quinolone-related arthropathy.
All participants (or legal representatives) gave written informed consent and the study was conducted in accordance with the Declaration of Helsinki, and with local legal and regulatory requirements.

\section{End points}

The primary objective was comparison of the change in FEV1 from baseline (day 0) to end of treatment (EOT; day 29) between participants with $\mathrm{CF}$ randomised to either ciprofloxacin DPI or corresponding placebo in the intent-to-treat (ITT) population (defined as all 
randomised patients who had received at least one dose of the study medication and had at least one observation after drug administration).

Secondary respiratory objectives included: comparing the change in FEV1 from baseline to days 8 and 15 (treatment phase) and at the 2-week and 4-week follow-up visits; assessing the change from baseline in forced vital capacity (FVC) or maximum forced expiratory flow $\left(\mathrm{FEF}_{25-75 \%}\right)$ rate at all subsequent clinic visits; and time to first pulmonary exacerbation requiring any antipseudomonal intervention or hospitalisation. Pulmonary function tests (FEV1, FVC and $\mathrm{FEF}_{25-75 \%}$ ) were performed at every clinic visit or at discontinuation. Microbiology on sputum samples obtained at all study visits was performed at a central laboratory. Objectives were assessment of the change in $P$. aeruginosa density in sputum from baseline to all subsequent clinic visits and the incidence of ciprofloxacin-resistant $P$. aeruginosa isolates in sputum. Patients completed the CF Quality of Life Questionnaire Revised (CFQ-R; a validated disease-specific instrument that measures health-related quality of life for adolescents and adults with $\mathrm{CF}$ ) at baseline, EOT and at the 4-week follow-up visit.

\section{Safety}

Assessment of the safety profiles for ciprofloxacin DPI and corresponding placebo was a secondary objective of the study. The safety analysis comprised monitoring for adverse events (AEs), and haematology, clinical chemistry, urinalysis, pulse oximetry, vital signs, physical examinations and musculoskeletal examination for patients $\leq 18$ years of age. These were performed at all clinic visits (except for haematology and clinical chemistry at day 15 (treatment phase) and 2-week follow-up visits). AEs were documented as treatment-emergent events (TEAEs) up to 7 days after EOT and, along with serious AEs occurring at any time, were followed up to 30 days post-therapy. Bronchospasm was defined as a drop of $\geq 15 \%$ in FEV1 and pulmonary exacerbations were reported as AEs. Patients who received an antipseudomonal antibiotic for a pulmonary exacerbation were discontinued from the trial.

\section{Statistical analyses}

The primary efficacy analysis was based on the ITT population. The randomisation schedule provided a power of $>95 \%$ to detect a $0.15 \mathrm{~L}$ absolute difference (assumed SD: $0.2 \mathrm{~L}$ ) in change in FEV1 from baseline to EOT for $32.5 \mathrm{mg}$ ciprofloxacin DPI versus placebo (combined: $n=156$ ), and a power of $>80 \%$ to detect the analogous difference between the $48.75 \mathrm{mg}$ ciprofloxacin DPI and placebo groups (combined: $\mathrm{n}=120$ ).

All efficacy variables were presented as summary statistics (arithmetic mean, SD, median, minimum and maximum for quantitative variables) and analysed by treatment group, dose of the study drug and corresponding placebo, and total, or combined by group.
Frequency tables for qualitative data were provided. All statistical tests were two-sided and performed at the 0.05 significance level.

Change in FEV1 was analysed by three-way analysis of covariance, with the following factors: treatment group, macrolide use (no/yes), region (centres were pooled into three regions: northern USA and Canada, southern USA, and outside North America (Europe, Israel and Australia)). The dependent variable was FEV1 at EOT; baseline FEV1 served as a covariate. The following null hypotheses for treatment effect were tested in a three-step hierarchical testing scheme: ciprofloxacin DPI $32.5 \mathrm{mg}=$ placebo $32.5 \mathrm{mg}$ plus ciprofloxacin DPI $48.75 \mathrm{mg}=$ placebo $48.75 \mathrm{mg}$ (combined hypothesis); ciprofloxacin DPI $32.5 \mathrm{mg}=$ placebo $32.5 \mathrm{mg}$ and ciprofloxacin DPI $48.75 \mathrm{mg}=$ placebo $48.75 \mathrm{mg}$ (two single hypotheses); and ciprofloxacin DPI 32.5 $\mathrm{mg}=$ ciprofloxacin DPI $48.75 \mathrm{mg}$. Imputation for premature termination was by last observation carried forward. FVC and $\mathrm{FEF}_{25-75 \%}$ end points were analysed in an analogous way.

Change in the density of $P$. aeruginosa in sputum was analysed by a log-linear model. The dependent variable was $P$. aeruginosa density ( $\log _{10}$ [colony-forming unit; CFU]+1]) in sputum at EOT (factors: treatment group, centre, macrolide use); pretreatment of $P$. aeruginosa density in sputum served as a covariate.

Time to antibacterial intervention for exacerbation was analysed by the Cox proportional hazards model, with baseline FEV1 as a covariate and the following factors: treatment, region and chronic macrolide use (no/yes).

\section{RESULTS}

\section{Subject disposition}

A total of 288 patients were randomised. Of these, 286 received either study drug or placebo, and were included in the ITT and safety analyses sets. The first and last subject visits were 5 May 2008 and 25 January 2011, respectively. The main reason for discontinuation was AEs; these included pulmonary exacerbations requiring an antipseudomonal antibiotic (figure 1B). Baseline demographics were similar between groups (table 1). The overall mean age was 29.3 years with $16.8 \%$ of patients aged $\leq 20$ years. Overall, $64 \%$ and $70 \%$ of patients in the ciprofloxacin DPI and placebo groups had received previous antipseudomonal maintenance therapy, respectively. Prior macrolide treatment status was similar for all groups (range 69.9-72.3\%) except the $48.75 \mathrm{mg}$ placebo group (54.3\%). Owing to the 30-day exclusionary period for systemic/inhaled antibiotics, data on prior usage for specific agents were not systematically collected or available for all patients. Treatment compliance $\geq 80 \%$ occurred in $96.7 \%$ and $90.3 \%$ of participants in the ciprofloxacin DPI 32.5 and $48.75 \mathrm{mg}$ groups, respectively, and in $90.8 \%$ and $85.7 \%$ of participants in the corresponding placebo groups. There were 
Table 1 Baseline subject demographics and characteristics (intent-to-treat/safety population)

\begin{tabular}{|c|c|c|c|c|}
\hline & \multicolumn{2}{|l|}{ Dose $32.5 \mathrm{mg}$} & \multicolumn{2}{|l|}{ Dose 48.75 mg } \\
\hline & $\begin{array}{l}\text { Ciprofloxacin DPI } \\
\mathrm{N}=93\end{array}$ & $\begin{array}{l}\text { Placebo } \\
\mathrm{N}=65\end{array}$ & $\begin{array}{l}\text { Ciprofloxacin DPI } \\
\mathrm{N}=93\end{array}$ & $\begin{array}{l}\text { Placebo } \\
\mathrm{N}=35\end{array}$ \\
\hline \multicolumn{5}{|l|}{ Sex, n (\%) } \\
\hline Male & $44(47.3)$ & $39(60.0)$ & $51(54.8)$ & $19(54.3)$ \\
\hline Female & $49(52.7)$ & $26(40.0)$ & $42(45.2)$ & $16(45.7)$ \\
\hline Age, years (mean) & 27.7 & 31.7 & 29.3 & 29.1 \\
\hline Weight, kg (mean) & 61.9 & 64.7 & 61.3 & 61.4 \\
\hline BMI (mean kg/m²) & 22.3 & 22.8 & 21.7 & 21.6 \\
\hline \multicolumn{5}{|l|}{ Ethnicity, n (\%) } \\
\hline Caucasian & $90(96.8)$ & $65(100)$ & $90(96.8)$ & $35(100)$ \\
\hline Black or African American & $3(3.2)$ & $0(0)$ & $1(1.1)$ & $0(0)$ \\
\hline Asian & $0(0)$ & $0(0)$ & $1(1.1)$ & $0(0)$ \\
\hline American Indian or Alaskan native & $0(0)$ & $0(0)$ & $1(1.1)$ & $0(0)$ \\
\hline FEV1\% predicted, mean & 55.0 & 54.8 & 54.7 & 52.7 \\
\hline Range & $31.0-76.6$ & $36.0-74.2$ & $33.0-79.0$ & $36.0-78.0$ \\
\hline Q1-Q3 & $47.0-63.0$ & $46.0-63.5$ & $43.0-65.3$ & $45.9-60.0$ \\
\hline \multicolumn{5}{|l|}{ Macrolide use, $n(\%)$} \\
\hline Yes & $65(69.9)$ & $47(72.3)$ & $66(71.0)$ & $19(54.3)$ \\
\hline No & $28(30.1)$ & $18(27.7)$ & $27(29.0)$ & $16(45.7)$ \\
\hline Prior antipseudomonal maintenance therapy, ${ }^{*} \mathrm{n}(\%)$ & $60(64.5)$ & $44(67.7)$ & $59(63.4)$ & $26(74.3)$ \\
\hline $\begin{array}{l}\text { Mean Pseudomonas aeruginosa colony count, } \\
\log _{10} \text { CFU/g (SD) }\end{array}$ & $6.73(2.16)$ & $7.08(2.07)$ & $6.77(1.89)$ & $7.37(1.67)$ \\
\hline Mean number of exacerbations in previous year & 1.6 & 1.6 & 1.9 & 1.3 \\
\hline
\end{tabular}

no obvious factors contributing to the slightly lower compliance rates in the placebo groups.

\section{Primary objective}

The primary end point testing did not demonstrate a treatment effect of ciprofloxacin DPI versus the corresponding placebo group or any difference between the doses in change in FEV1 from baseline to EOT in the ITT population ( $p=0.154$; figure 2$)$. Decreases from baseline were $0.01 \mathrm{~L}$ in both ciprofloxacin groups, versus $0.06 \mathrm{~L}$ and $0.07 \mathrm{~L}$ in the placebo 32.5 and $48.75 \mathrm{mg}$ groups, respectively. However, the change in FEV1 from baseline to EOT for pooled ciprofloxacin DPI -treated patients was significantly less than for pooled placebo patients $(p=0.02)$; the respective decreases were $0.02 \mathrm{~L}$ for the pooled ciprofloxacin DPI groups and $0.08 \mathrm{~L}$ ciprofloxacin DPI for the corresponding pooled placebo groups.

The time course of FEV1 values (empirical means) as a percentage of predicted values is shown in figure 2 . In both ciprofloxacin DPI treatment groups, FEV1 increased from baseline to day 8 , but declined after this time point to EOT. For the corresponding placebo groups, FEV1 decreased from baseline to EOT, except for a slight increase at day $15 \mathrm{in}$ the $48.5 \mathrm{mg}$ ciprofloxacin DPI placebo group. A slight increase in FEV1 was observed for all groups over the course of follow-up, with the exception of the $32.5 \mathrm{mg}$ ciprofloxacin DPI group, in which FEV1 values remained relatively stable during this period.

\section{Secondary objectives}

\section{Microbiology}

Both doses of ciprofloxacin DPI resulted in a decrease in $P$. aeruginosa density during treatment, but this reduction was reversed after ending treatment (figure 3). $P$. aeruginosa density decreased from baseline values in both ciprofloxacin DPI treatment arms and the placebo $32.5 \mathrm{mg}$ arm after treatment initiation. In the ciprofloxacin DPI $32.5 \mathrm{mg}$ treatment arm, the mean bacterial density continued to decrease until day $15(-1.0 \log$ $\mathrm{CFU} / \mathrm{g})$, whereas a nadir was reached at day 8 for the $48.75 \mathrm{mg}$ ciprofloxacin DPI treatment arm (-1.4 log $\mathrm{CFU} / \mathrm{g}$; figure 3). Although significant differences in $P$. aeruginosa density between ciprofloxacin DPI and placebo were observed at days 14-16 ( $\mathrm{p}<0.001$ and $\mathrm{p}=0.002$ for the 32.5 and $48.75 \mathrm{mg}$ doses, respectively), there were no significant differences in $P$. aeruginosa density at $\operatorname{EOT}(\mathrm{p}=0.214$ and $\mathrm{p}=0.388$ for the 32.5 and $48.75 \mathrm{mg}$ doses, respectively) and there were no significant changes in $P$. aeruginosa density in sputum from baseline at post-EOT follow-up visits. There was no difference between doses at any time point $(\mathrm{p}=0.726$ at EOT). Log CFU reductions in mucoid $P$. aeruginosa were greater than the reductions in non-mucoid $P$. aeruginosa.

There were no significant differences in the incidence of ciprofloxacin-resistant $P$. aeruginosa isolates in sputum at the 4-week follow-up visit. The MIC50/MIC90 values at baseline and EOT were $1 / 4$ and $2 / 8 \mu \mathrm{g} / \mathrm{mL}$ for the ciprofloxacin DPI $32.5 \mathrm{mg}$ group, and 2/8 and 2/16 $\mu \mathrm{g} /$ 


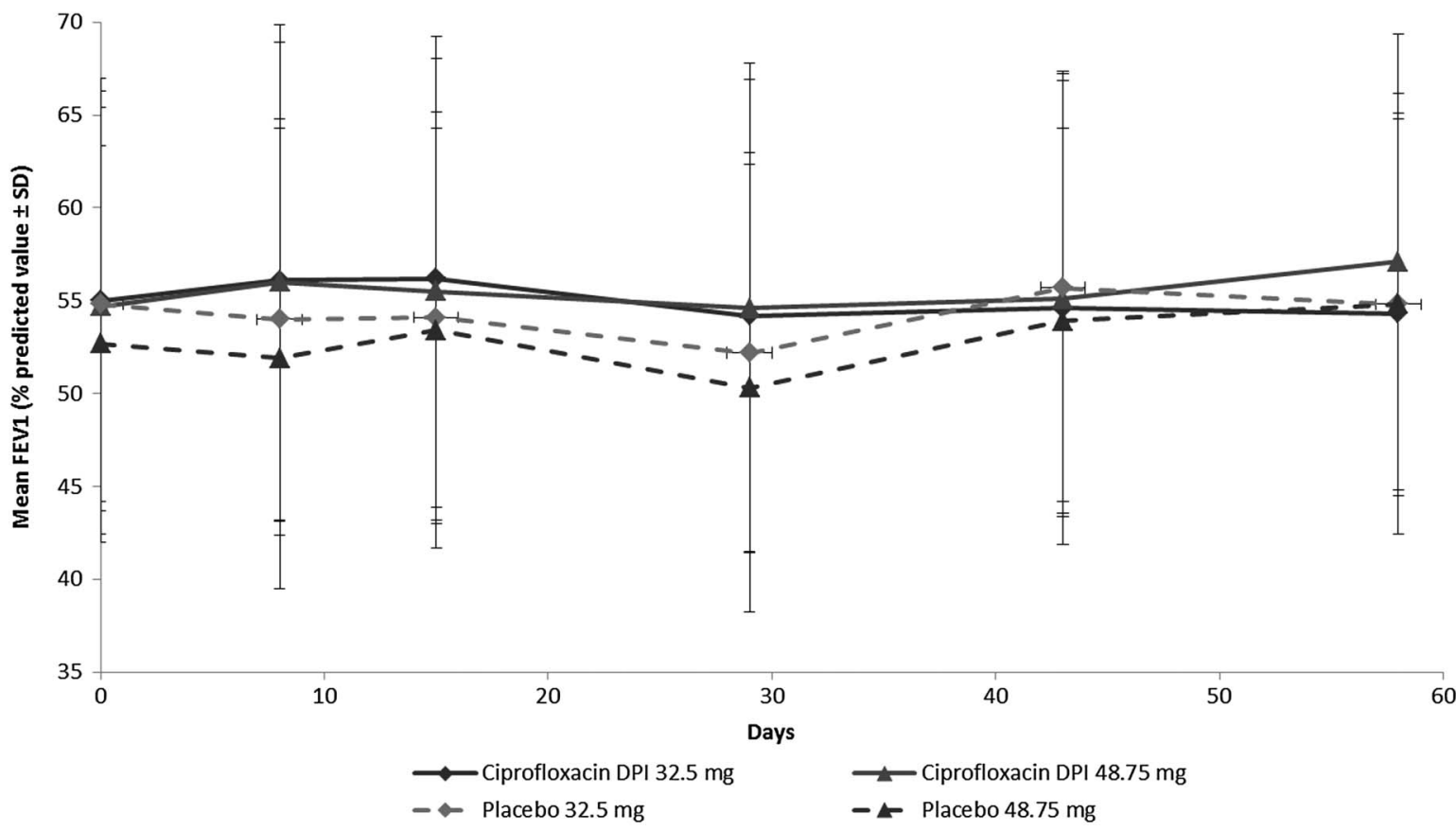

Figure 2 Time course of FEV1 (mean, \% predicted) (intent-to-treat population) by study group. Empirical mean FEV1 is presented as percentage predicted value, with error bars representing SD. DPI, dry powder for inhalation; FEV1, forced expiratory volume in $1 \mathrm{~s}$.

$\mathrm{mL}$ for the $48.75 \mathrm{mg}$ group. Reductions in P. aeruginosa were similar in patients with baseline isolates that were susceptible $(\mathrm{MIC} \leq 1 \mu \mathrm{g} / \mathrm{mL})$, intermediate $(\mathrm{MIC}=2 \mu \mathrm{g} /$ $\mathrm{mL}$ ), or resistant (MIC $\geq 4 \mu \mathrm{g} / \mathrm{mL}$ ) to ciprofloxacin (data not shown). The lack of correlation between reduction in $P$. aeruginosa and MIC susceptibility of organism to ciprofloxacin DPI is not surprising, considering the very high sputum concentrations of ciprofloxacin that can be achieved by inhalation of ciprofloxacin DPI. ${ }^{13}$

\section{Respiratory end points}

Exacerbations requiring any antipseudomonal intervention or hospitalisation occurred in 15/93 (16\%) and 16/93 (17\%) participants receiving ciprofloxacin DPI 32.5 and $48.75 \mathrm{mg}$, respectively, and in 13/65 (20\%) and

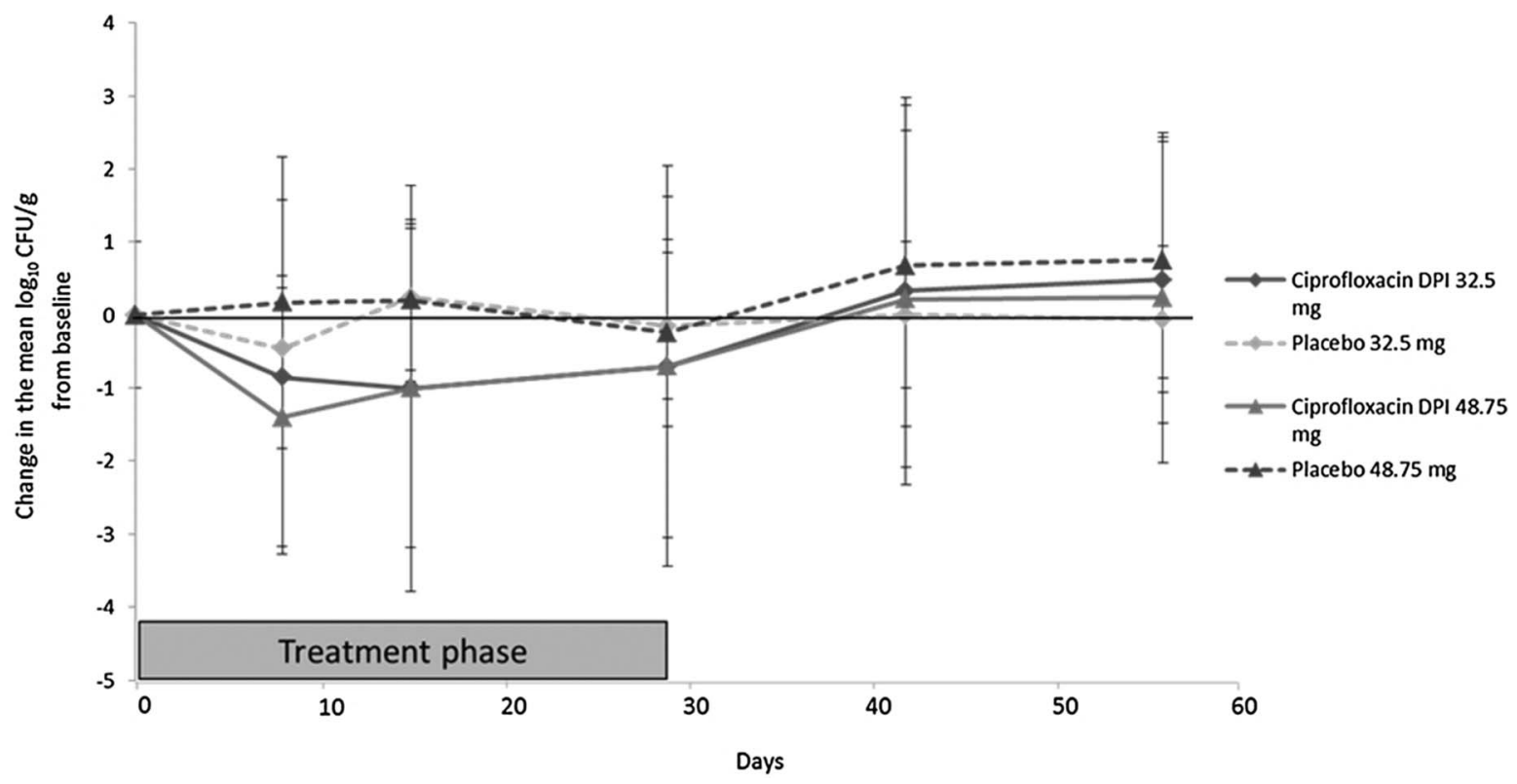

Figure 3 Change in mean density of Pseudomonas aeruginosa in sputum ( $\log _{10} \mathrm{CFU} / \mathrm{g}$ ) (intent-to-treat population) by study group. CFU, colony-forming unit; DPI, dry powder for inhalation. 
10/35 (29\%) participants receiving corresponding placebo. The study was not powered or designed to detect an effect of treatment on time to first exacerbation, and the differences observed between the ciprofloxacin DPI and placebo study arms were not statistically significant $(32.5 \mathrm{mg}$ vs placebo: $\mathrm{p}=0.464$, HR $0.757,95 \%$ CI 0.36 to $1.59 ; 48.75 \mathrm{mg}$ vs placebo: $\mathrm{p}=0.143$, HR $0.552,95 \%$ CI 0.25 to 1.22 ).

The difference in mean percentage-predicted $\mathrm{FEF}_{25-}$ 75\% from baseline to EOT in the ciprofloxacin DPI groups increased by $0.29 \%$ (pooled), $0.24 \%$ (32.5 mg) and $0.35 \%(48.75 \mathrm{mg})$. Conversely, the difference in mean percentage-predicted $\mathrm{FEF}_{25-75 \%}$ in the matching placebo groups decreased by $2.0 \%$ (pooled), $2.1 \%$ $(32.5 \mathrm{mg})$ and $1.8 \%$ (48.75 mg). There was no apparent treatment effect on FVC. No significant differences were seen in any of the other secondary end points (change in FEV1 from baseline to days 8 and 15, and at the 2-week and 4-week follow-up visits; change from baseline in $\mathrm{FVC}$ or $\mathrm{FEF}_{25-75 \%}$ rate at all subsequent clinic visits; time to first pulmonary exacerbation requiring any antipseudomonal intervention or hospitalisation and microbiological end points discussed above).

\section{Health-related quality of life}

The $32.5 \mathrm{mg}$ and pooled ciprofloxacin DPI groups both had significantly higher CFQR respiratory symptom subscale scores at EOT versus respective placebo groups ( $\mathrm{p}=0.007$ and $\mathrm{p}=0.019$, respectively) in the ITT population. Differences were no longer significant by the 4-week follow-up. A weak but significant correlation was seen between CFQ-R respiratory symptom subscale score and FEV1 at EOT for the ITT $(\mathrm{r}=0.255)$ population $(p<0.001)$. This correlation was still present in the ITT population at the 4-week follow-up $(\mathrm{r}=0.214, \mathrm{p}=0.005)$.

\section{Safety}

There were no significant differences in type or incidence of TEAE by treatment group (all TEAEs $\mathrm{p}=0.115$; table 2) in the safety population. A total of $43.5 \%$ of patients and $32 \%$ of patients receiving ciprofloxacin DPI and corresponding placebo, respectively, experienced a drug-related TEAE. Of the two ciprofloxacin DPI doses, the $32.5 \mathrm{mg}$ dose appeared to be somewhat better tolerated; $37.6 \%$ of patients in this treatment group experienced a drug-related TEAE, compared with $49.5 \%$ of patients who received ciprofloxacin DPI $48.75 \mathrm{mg}$. The most common TEAEs in the ciprofloxacin DPI groups were dysgeusia and abnormal product taste, both of which were likely related to characteristics of the study medication (Ciprofloxacin is known for its bitter taste). Although the placebo formulation contained quinine to account for this, it is likely that the active drug and placebo formulations differed in bitterness or other taste

Table 2 Summary of treatment-emergent AEs (safety population)

\begin{tabular}{|c|c|c|c|c|}
\hline \multirow[b]{2}{*}{ MedDRA-preferred term } & \multicolumn{2}{|l|}{ Dose $32.5 \mathrm{mg}$} & \multicolumn{2}{|l|}{ Dose $48.75 \mathrm{mg}$} \\
\hline & $\begin{array}{l}\text { Ciprofloxacin DPI } \\
\mathrm{N}=93 \\
\text { n (\%) }\end{array}$ & $\begin{array}{l}\text { Placebo } \\
\mathrm{N}=65 \\
\mathrm{n}(\%)\end{array}$ & $\begin{array}{l}\text { Ciprofloxacin DPI } \\
\text { N=93 } \\
\text { n (\%) }\end{array}$ & $\begin{array}{l}\text { Placebo } \\
\mathrm{N}=35 \\
\mathrm{n}(\%)\end{array}$ \\
\hline Any $A E$ & $68(73.1)$ & $53(81.5)$ & $81(87.1)$ & $29(82.9)$ \\
\hline Any drug-related $\mathrm{AE}$ & $35(37.6)$ & $22(33.8)$ & $46(49.5)$ & $10(28.6)$ \\
\hline \multicolumn{5}{|c|}{ Drug-related AEs in $>5 \%$ participants in any treatment group } \\
\hline Product taste abnormal & $7(7.5)$ & $4(6.2)$ & $16(17.2)$ & $2(5.7)$ \\
\hline Dysgeusia & $13(14.0)$ & $4(6.2)$ & $9(9.7)$ & $1(2.9)$ \\
\hline Cough & $3(3.2)$ & $7(10.8)$ & $2(2.2)$ & $3(8.6)$ \\
\hline Gastrointestinal disorders* & $3(3.2)$ & $2(3.1)$ & $5(5.4)$ & $1(2.9)$ \\
\hline Sputum increased & 0 & $1(1.5)$ & $2(2.2)$ & $2(5.7)$ \\
\hline Chest discomfort & $1(1.1)$ & $4(6.2)$ & $1(1.1)$ & 0 \\
\hline Any serious AE† & $4(4.3)$ & $4(6.2)$ & $11(11.8)$ & $2(5.7)$ \\
\hline Any drug-related serious AE† & 0 & $1(1.5)$ & $3(3.2)$ & 0 \\
\hline Pancreatitis & 0 & 0 & $1(1.1)$ & 0 \\
\hline Infective pulmonary exacerbation of CF & 0 & 0 & $1(1.1)$ & 0 \\
\hline Bronchospasm & 0 & 0 & $1(1.1)$ & 0 \\
\hline Haemoptysis & 0 & $1(1.5)$ & $2(2.2)$ & 0 \\
\hline \multicolumn{5}{|l|}{ AEs of particular interest } \\
\hline $\begin{array}{l}\text { Drug-induced bronchospasm ( } \geq 15 \% \text { drop in FEV1 } \\
\text { following drug administration) }\end{array}$ & $3(3.2)$ & $3(4.6)$ & $3(3.2)$ & 0 \\
\hline Premature discontinuation due to $\mathrm{AE}$ & $10(10.8)$ & $9(13.8)$ & $15(16.1)$ & $10(28.6)$ \\
\hline Deaths & 0 & 0 & 0 & 0 \\
\hline \multicolumn{5}{|c|}{$\begin{array}{l}\text { Multiple occurrences of the same event in the same subject are only counted once. } \\
{ }^{*} \text { Refers to MedDRA SOC. All drug-related AEs within this SOC occurred at a frequency of }<5 \% \text { in the individual treatment groups. } \\
\text { †Serious AEs were defined as AEs that were life-threatening, that required inpatient hospitalisation or prolongation of existing hospitalisation, } \\
\text { that resulted in persistent or significant disability or death, or that was a congenital anomaly, birth defect, or an important medical event. } \\
\text { AE, adverse event; CF, cystic fibrosis; DPI, dry powder for inhalation; FEV1, forced expiratory volume in } 1 \mathrm{~s} \text {; MedDRA, medical dictionary for } \\
\text { regulatory activities; SOC, system organ class. }\end{array}$} \\
\hline
\end{tabular}


attributes. Similar side effects related to taste were also reported in the ciprofloxacin DPI phase II trial in patients with non-CF bronchiectasis. ${ }^{17}$

Aside from three cases of haemoptysis that were considered to be related to the study drug, there were no new unexpected safety events reported during the study. Four participants had serious drug-related TEAEs. The incidence of treatment-emergent bronchospasm, defined as $\geq 15 \%$ drop in FEV1 following study drug administration, was low (0-3 participants per group) and there was no statistically significant difference by treatment group $(\mathrm{p}=0.741)$. No deaths occurred during the study.

\section{DISCUSSION}

A significant need remains for the development of additional and easier-to-use inhalational antibiotics. Prolonged use of systemically administered antibiotics to patients with $\mathrm{CF}$ infected with $P$. aeruginosa is known to result in resistance to treatment and, therefore, diminished efficacy. ${ }^{23}$ To maintain efficacy on repeated administration, the strategy is usually to add another antibiotic to the treatment, which would have either an additive or a synergistic effect. ${ }^{24}$ Because the relevance of organism antibiotic sensitivity patterns has been questioned in recent years, the use of two antibiotics with different mechanisms of action to improve outcome is still common practice in most CF centres. ${ }^{25}$

Antibiotics administered through a DPI route have the potential for greater efficacy and safety, owing to targeted delivery of higher concentrations of the drug to the lungs and lower systemic exposure. Additionally, the more convenient method of administration (compared with traditional nebulisers) is likely to improve patient compliance. ${ }^{10}$ The primary end point of this study was to compare the change in FEV1 from baseline to EOT between patients receiving ciprofloxacin DPI and those receiving matching placebo. Based on the results of this study, the null hypotheses of no difference between the treatment groups could not be rejected.

Although the primary end point was not met, ciprofloxacin DPI was associated with some positive effects in analyses of the primary variable of lung function (FEV1), as well as on sputum bacterial load and health-related quality of life. In particular, there was a significant difference $(\mathrm{p}<0.05)$ between pooled ciprofloxacin DPI arms and pooled placebo arms in change in FEV1 from baseline to EOT. However, changes in FEV1 between 32.5 or $48.75 \mathrm{mg}$ ciprofloxacin DPI and matching placebo, the prespecified primary study end point, did not achieve statistical significance. Both ciprofloxacin DPI arms transiently showed nominally significant results of reduced total bacterial load $(P$. aeruginosa) up to day 15 compared with matching placebo arms.

There was some evidence of both mucoid and nonmucoid $P$. aeruginosa reduction from baseline with ciprofloxacin DPI and, in the case of the former, these decreases were independent of resistance status at baseline. However, there was no sustained long-term decrease in the mean total bacterial load, as this change in $P$. aeruginosa density in the sputum from baseline was no longer statistically significant at EOT (ciprofloxacin DPI vs matching placebo; $p=0.068)$. This finding has been noted in trials of other therapeutic agents, such as colistin. $^{26}$

Significant improvements in health-related quality of life, assessed with the CFQ-R, were observed in the ciprofloxacin DPI $32.5 \mathrm{mg}$ treatment group versus placebo as well as in pooled analyses at EOT $(p=0.007$ in the $32.5 \mathrm{mg}$ ciprofloxacin DPI group vs matching placebo), although these improvements were not sustained at the 4-week follow-up visit $(\mathrm{p}=0.935$ in the $32.5 \mathrm{mg}$ ciprofloxacin DPI group vs matching placebo).

Several factors may have contributed to the primary end point not being met. Overall, the patients represented a heavily managed older population: approximately $77 \%$ of patients had received prior antipseudomonal maintenance therapy and mean age was 29.3 years; ( $16.8 \%$ of patients were aged $\leq 20$ years), indicating a relatively advanced disease state in most patients. $^{27}$ The limited progress in treatment over the last decade has reduced the potential to see clinically meaningful improvements in FEV1. Additionally, the lungs of older patients with $\mathrm{CF}$ are damaged to the point that significant improvements in FEV1 are less likely. Although suboptimal drug delivery or penetration could potentially have influenced the results of our study, data from phase I studies in CF participants indicate that twice daily ciprofloxacin DPI administration results in mean sputum ciprofloxacin concentrations of $34.9-149.7 \mathrm{mg} / \mathrm{L}$, which are well above plasma levels achieved by systemic ciprofloxacin use $(1.2-3.0 \mathrm{mg} / \mathrm{L}) .^{28} 29$ In addition, scintigraphic data support high and reproducible lung deposition of approximately $50 \%$ in healthy study participants and in patients with non-CF bronchiectasis or chronic obstructive pulmonary disease. ${ }^{30}$ We therefore believe it is unlikely that poor drug delivery or penetration influenced the results. The overall reason for lack of FEV1 improvement in patients with CF treated with ciprofloxacin DPI is unknown, but this result demonstrates the complexity of CF inhalation studies and the possible need to consider alternative clinical end points in this population. 31

Small airway occlusion by purulent mucus is common in the lungs of patients with CF, and this is likely to be more severe in patients with advanced disease. Disease severity may therefore influence distribution and location of the inhaled drug, as with any inhaled antibiotic. This, in turn, can affect the local concentration of ciprofloxacin. $^{32}$ In addition to improved airway clearance before DPI administration, altering the dosing frequency may help to mitigate these challenges. In a study of levofloxacin inhalation solution, improved outcomes were observed with higher doses (240 mg twice daily vs 
$120 \mathrm{mg}$ twice daily). ${ }^{33}$ In our study, however, there was no statistically significant difference between doses for the primary end point. The reasons for this are unclear, but may relate to a limited potential for improvement in this heavily pretreated patient population.

Overall, the safety parameters-type of TEAEs and their intensity, relationship to the study drug, seriousness and outcome-remained similar in all groups. There were three cases of haemoptysis considered to be related to the study drug, two of which were serious. However, it should be noted that haemoptysis is not an uncommon manifestation of pulmonary disease in CF. The $32.5 \mathrm{mg}$ ciprofloxacin DPI seemed to be slightly better tolerated than the $48.75 \mathrm{mg}$ ciprofloxacin DPI, with fewer cases of discontinuation due to AEs and fewer drug-related TEAEs. In both treatment groups, the incidence of cough was low. Inhalation of dry powder can result in cough, owing to the nature of the dosage form ${ }^{10}$; however, in this study, although the inhaled mass was greater than that inhaled with the TOBI Podhaler, ${ }^{12} \mathrm{a}$ low incidence of cough was reported. This may be due to the fact that ciprofloxacin DPI is less osmotic than tobramycin; therefore, a lesser effect is being exerted on the lung epithelium.

Because of the short-term nature of this study, we are unable to speculate on the impact of ciprofloxacin DPI therapy on the effectiveness of future oral ciprofloxacin in this patient population. Studies with tobramycin solution for inhalation indicate that intermittent use in patients with $\mathrm{CF}$ results in modest increases in $P$. aeruginosa MIC values, but the increased MICs are not associated with clinically relevant effects. ${ }^{34}$ However, to date, no study has specifically examined the effect of inhaled antibiotics on subsequent systemic therapy with the same drug or drug class.

In conclusion, in patients with $\mathrm{CF}$, twice daily treatment with ciprofloxacin DPI (32.5 or $48.75 \mathrm{mg}$ ) for 28 days did not result in significant improvements versus placebo in change in FEV1 from baseline to EOT, although some encouraging signs of efficacy were observed. It is possible that FEV1 is not the best end point for evaluating the efficacy of a short-term treatment on lung function in such a patient population. Ciprofloxacin DPI was safe and well tolerated; the $32.5 \mathrm{mg}$ dose had a slightly more favourable overall tolerability profile than the $48.75 \mathrm{mg}$ ciprofloxacin DPI dose. Additional studies assessing the efficacy of longer term ( $>28$ days) treatment as indicated by alternative end points, as well as further investigations on optimal delivery of ciprofloxacin DPI in stable patients with $\mathrm{CF}$, may be worth pursuing.

Acknowledgements The authors would like to thank Barbara Hampel (formerly with Bayer HealthCare, Berlin, Germany) and Peter Reimnitz (formerly with Bayer Pharma, Wuppertal, Germany), for important intellectual contributions; and to acknowledge Fusion MD, Montreal, Canada, Highfield Communication, Oxford, England, and Kate Haynes of Chameleon Communications International, for providing medical writing services, with funding from Bayer Pharma AG. The authors would also like to thank the CF Foundation Therapeutic Network.
Collaborators The principal investigators in this study were: S Bell, $\mathrm{H}$ Greville, J Morton, P Robinson, D Serisier, P Thompson (Australia); AP Freitag, B Lyttle, K Palinder (Canada); T Pressler (Denmark); R Fischer, W Gleiber, D Staab, H Wirtz (Germany); L Bentur, H Blau, 0 Efrati, E Kerem, (Israel); A Hollsing, A Lindblad, L Mared (Sweden); M Carroll (UK); F Accurso, PJ Anderson, B Barnett, D Bisberg, S Boas, H Carveth, R Cohen, C Daines, Z Danov, SB Fiel, P Fornos, C Forseen, S Forsythe, D Froh, D Geller, R Gibson Jr, G Gong, D Hadjiliadis, D Homnick, M Howenstine, S Jain, ME Kleinhenz, N Kraynack, C Landon, D Layish, M Light, J Mcardle, B McWilliams Jr, K Meyer, S Miller, C Nakamura, S Nasr, MS Pian, A Prestridge, A Rao, S Reyes, J Rosen, J Royall, A Sannuti, D Schaeffer, G Sharma, A Stenbit, N Turcios, A Uluer, L Varlotta, R Vender, J Voynow, M Weatherly, J Wooldridge, W Yee, R Zanni (USA).

Contributors HLD and DS were involved in data acquisition. All the authors contributed to study design or were involved in data analysis and interpretation. All the authors participated in manuscript revision and approved the final version.

Funding Bayer HealthCare was the sponsor of this study, supplied the investigational agent, and provided funding for the clinical trial and for manuscript support by Fusion MD, Highfield Communication, and Chameleon Communications International.

Competing interests HLD has participated in studies funded by Bayer and has been a member of scientific advisory boards; EO, JA and MC are employees of Bayer.

Patient consent Obtained.

Ethics approval Ethics approval was obtained from Institutional Review Boards or Research Ethics Committees for all participating centres.

Provenance and peer review Not commissioned; externally peer reviewed.

Open Access This is an Open Access article distributed in accordance with the Creative Commons Attribution Non Commercial (CC BY-NC 4.0) license, which permits others to distribute, remix, adapt, build upon this work noncommercially, and license their derivative works on different terms, provided the original work is properly cited and the use is non-commercial. See: http:// creativecommons.org/licenses/by-nc/4.0/

\section{REFERENCES}

1. Gibson RL, Burns JL, Ramsey BW. Pathophysiology and management of pulmonary infections in cystic fibrosis. Am J Respir Crit Care Med 2003;168:918-51.

2. Davis PB. Cystic fibrosis since 1938. Am J Respir Crit Care Med 2006;173:475-82.

3. Cystic Fibrosis Foundation 2011 Patient Registry Report. Cystic Fibrosis Foundation, 2011. http://www.cff.org/UploadedFiles/ research/ClinicalResearch/2011-Patient-Registry.pdf (accessed Mar 2015).

4. Flume PA, Robinson KA, O'Sullivan BP, et al. Cystic fibrosis pulmonary guidelines: airway clearance therapies. Respir Care 2009;54:522-37.

5. Bendiak GN, Ratjen F. The approach to Pseudomonas aeruginosa in cystic fibrosis. Semin Respir Crit Care Med 2009;30:587-95.

6. Laube BL, Janssens HM, de Jongh $\mathrm{FH}$, et al. What the pulmonary specialist should know about the new inhalation therapies. Eur Respir J 2011;37:1308-31.

7. Heijerman H, Westerman E, Conway S, et al. Inhaled medication and inhalation devices for lung disease in patients with cystic fibrosis: A European consensus. J Cyst Fibros 2009;8:295-15.

8. Chrystyn H, Price D. Not all asthma inhalers are the same: factors to consider when prescribing an inhaler. Prim Care Respir $J$ 2009;18:243-9.

9. Geller DE, Konstan MW, Smith J, et al. Novel tobramycin inhalation powder in cystic fibrosis subjects: pharmacokinetics and safety. Pediatr Pulmonol 2007;42:307-13.

10. Parkins MD, Elborn JS. Tobramycin inhalation powder: a novel drug delivery system for treating chronic Pseudomonas aeruginosa infection in cystic fibrosis. Expert Rev Respir Med 2011;5: 609-22.

11. Geller DE, Flume PA, Griffith DC, et al. Pharmacokinetics and safety of MP-376 (levofloxacin inhalation solution) in cystic fibrosis subjects. Antimicrob Agents Chemother 2011;55:2636-40. 
12. Novartis Pharmaceuticals Corporation. TOBI@ PODHALER ${ }^{\mathrm{TM}}$ (tobramycin inhalation powder) TOBI尺 PODHALER ${ }^{\mathrm{TM}}$ (tobramycin inhalation powder) prescribing information. 2013. http://www.pharma. us.novartis.com/product/pi/pdf/tobipodhaler.pdf

13. Stass $\mathrm{H}$, Nagelschmitz J, Kappeler D, et al. Lung deposition of ciprofloxacin dry powder for inhalation in healthy subjects and patients suffering from chronic obstructive pulmonary disease or non-cystic fibrosis bronchiectasis. Poster presentation at International Congress of the American Thoracic Society, Philadelphia, USA, 2013.

14. Gupta A, Tarara T, Miller D, et al. A novel high-payload dry powder formulation of ciprofloxacin for management of chronic lung infections. American Association of Pharmaceutical Scientists Annual Meeting; Washington, USA, 2011; Poster R6156.

15. Weers JG, Tarara TE. The PulmoSphere ${ }^{\mathrm{TM}}$ platform for pulmonary drug delivery. Ther Deliv 2014;5:277-95.

16. Stass $\mathrm{H}$, Baumann-Noss $\mathrm{S}$, Delesen $\mathrm{H}$, et al. Pharmacokinetics of inhaled ciprofloxacin powder. 31st European Cystic Fibrosis Conference; Prague, Czech Republic, 2008; Poster P103.

17. Wilson R, Welte T, Polverino E, et al. Ciprofloxacin dry powder for inhalation in non-cystic fibrosis bronchiectasis: a phase II randomised study. Eur Respir J 2013;41:1107-15.

18. Stass $\mathrm{H}$, Nagelschmitz J, Willmann $\mathrm{S}$, et al. Inhalation of a dry powder ciprofloxacin formulation in healthy subjects: a phase I study. Clin Drug Investig 2013;33:419-27.

19. van Westreenen M, Tiddens HA. New antimicrobial strategies in cystic fibrosis. Paediatr Drugs 2010;12:343-52.

20. Bayer HealthCare Pharmaceuticals. CIPRO® (ciprofloxacin hydrochloride). 2009. http://www.univgraph.com/bayer/inserts/ ciprotab.pdf

21. Bayer Plc. (Ciprofloxacin) Ciproxin tablets $500 \mathrm{mg}$ Summary of Product Characteristics. 2010. https://www.medicines.org.uk/emc/ medicine/20346/SPC/Ciproxin+Tablets+500mg/

22. Bayer Plc. (Ciprofloxacin) Ciproxin Infusion Summary of Product Characteristics. 2010. https://www.medicines.org.uk/emc/medicine/ 2536

23. Høiby N. Recent advances in the treatment of Pseudomonas aeruginosa infections in cystic fibrosis. BMC Med 2011;9:32.
24. Herrmann G, Yang L, Wu H, et al. Colistin-tobramycin combinations are superior to monotherapy concerning the killing of biofilm Pseudomonas aeruginosa. J Infect Dis 2010;202:1585-92.

25. Rao P, McCaughan J, McCalmont M, et al. Comparison of antibiotic susceptibility patterns in Pseudomonas aeruginosa isolated from adult patients with cystic fibrosis (CF) with invasive Pseudomonas aeruginosa from non-CF patients. J Cyst Fibros 2012;11:349-52.

26. Alothman GA, Ho B, Alsaadi MM, et al. Bronchial constriction and inhaled colistin in cystic fibrosis. Chest 2005;127:522-9.

27. Geller DE, Nasr SZ, Piggott S, et al. Tobramycin inhalation powder in cystic fibrosis patients: response by age group. Respir Care 2014;59:388-98.

28. Stass H, Weimann B, Nagelschmitz J, et al. Tolerability and pharmacokinetic properties of ciprofloxacin dry powder for inhalation in patients with cystic fibrosis: a phase I, randomized, dose-escalation study. Clin Ther 2013;35:1571-81.

29. Stass H, Delesen H, Nagelschmitz J, et al. Safety and pharmaockinetics of ciprofloxacin dry powder for inhalation in cystic fibrosis: a phase I, randomized, single-dose, dose-escalation study. J Aerosol Med Pulm Drug Deliv 2015;28:106-15.

30. Stass $\mathrm{H}$, Nagelschmitz J, Kappeler D, et al. Lung deposition of Ciprofloxacin Dry Powder for Inhalation in healthy subjects and patients suffering from chronic obstructive pulmonary disease or non-cystic fibrosis bronchiectasis (abstract). Am J Respir Crit Care Med 2013;187:A1507.

31. Van Devanter D, Konstan M. Cystic fibrosis drug development: victims of our own success. Proc Resp Drug Deliv 2008;1:11-7.

32. Stass H, Baumann-Noss S, Delesen $\mathrm{H}$, et al. Ciprofloxacin PulmoSphere $\circledR$ inhalational powder: a healthy volunteer study. American Thoracic Society International Conference; Toronto, Canada, 2008; Poster G50.

33. Geller DE, Flume PA, Staab D, et al. Levofloxacin inhalation solution (MP-376) in patients with cystic fibrosis with Pseudomonas aeruginosa. Am J Respir Crit Care Med 2011;183:1510-16.

34. LiPuma JJ. Microbiological and immunologic considerations with aerosolized drug delivery. Chest 2001;120:118S-23S. 